\title{
Current perspectives on video and audio recording inside the surgical operating room: results of a cross-disciplinary survey
}

\author{
Floyd W. van de Graaf ${ }^{1}$. Özgür Eryigit ${ }^{1}$ Johan F. Lange ${ }^{1}$
}

Received: 10 August 2020 / Accepted: 13 October 2020 / Published online: 26 October 2020

(c) The Author(s) 2020

\begin{abstract}
The availability of intraoperative multimedia recording is increasing. Considering the growing call for physicians' accountability, it is inevitable that multimedia will play an important role in aiding quality control by improving the adequacy of operative reporting. However, the perspectives of medical professionals on this matter are poorly known. In this cross-disciplinary survey, we aimed to investigate the current viewpoints concerning the use of multimedia recording in the operating room. We conducted an electronic survey among all affiliated members of the Association of Surgeons of the Netherlands, the Dutch Urological Association and the Dutch Society of Obstetrics and Gynecology containing questions regarding current use of intraoperative recording and the level of likelihood or objection for certain scenarios. The response rate was $27.8 \%$. The survey encompasses $370(54.5 \%)$ surgeons, 71 (10.5\%) urologists, 80 (11.8\%) gynecologists, and $158(23.3 \%)$ residents in training. 52.4\% of respondents feel that the currently used operative report is insufficient for future quality requirements. $58.5 \%$ think it is unlikely they would behave differently during surgery when intra-operative video recording is applied. $82.8 \%$ think it is unlikely that their surgical methods would be altered. $63.8 \%$ of respondents preferred only video registration when intraoperative recording is implemented. The majority of respondents agree that the current method of operative reporting is insufficient for future quality requirements. There is support for intraoperative video recording, however, legal transparency is needed before either intraoperative video or audio recording could be implemented to protect not only the patients, but also the healthcare providers.
\end{abstract}

Keywords Laparoscopic surgery $\cdot$ Multimedia $\cdot$ Operating room $\cdot$ Video recording $\cdot$ Audio recording

\section{Introduction}

During the last decade, the use of multimedia in the context of the operating room has increased rapidly. Capturing video, still images or sound have become an essential part of daily practice in many surgical disciplines, with the potential to benefit either individual patient care or treatment as

Floyd W. van de Graaf and Özgür Eryigit have contributed equally to this study and both authors should be considered as first author.

Electronic supplementary material The online version of this article (https://doi.org/10.1007/s13304-020-00902-7) contains supplementary material, which is available to authorized users.

Floyd W. van de Graaf

f.vandegraaf@erasmusmc.nl

1 Department of Surgery, Erasmus University Medical Center (Erasmus MC), University Medical Center Rotterdam, P.O. Box 2040, 3000 CA Rotterdam, The Netherlands a whole. Alongside photo-documentation of laparoscopic female sterilization, probably the best-known example of multimedia documentation is that of the critical view of safety (CVS) on photo or video in laparoscopic cholecystectomy as an auxiliary to the narrative operative report [1]. This approach has become an essential part in laparoscopic cholecystectomy procedures in the Netherlands and is also recommended in the USA [2, 3]. Prior research demonstrated that the traditional narrative operative report does not adequately reflect reality in laparoscopic cholecystectomy [4-6]. One method to ameliorate the accuracy of these reports could be the use of synoptic reporting, utilizing a structured template to construct an operative report, diminishing the amount of data omitted and effectively increasing its integrity [7-13]. Utilizing intraoperative video recording in synergy with a written operative report also proved to be feasible and furthermore, superior to the classic narrative operative report alone $[5,6]$. For an even better understanding of the operative procedure upon review, simultaneous 
audio recordings could be a valuable option to further reduce discrepancies between video recording and operative report [14].

In addition to a boost in reporting quality, use of multimedia documentation could also be invaluable for other purposes, for instance, in the case of surgical quality control and quality assurance. In a study by the Michigan Bariatric Surgery Collaborative, peer-rating of procedural videos of laparoscopic gastric bypass surgery was performed to assess participating bariatric surgeons' technical skills [15]. The authors reported a relationship between the technical skill quantified on video and postoperative outcomes, confirming that greater technical skill does indeed result in significantly fewer postoperative complications. Taking it a step further, Toronto-based surgeon Dr. Teodor Grantcharov developed the surgical 'black box'. This recording device, much like its equivalent in aviation, registers data regarding the surgical procedure in real time from multiple inputs, i.e. sound (speech of surgeons and operating room personnel), videos from several angles (surgical site and surrounding areas in the operating room), and patients' vital signs from the anesthesia workstation, in order to discern the origins of adverse events.[16].

Considering the growing call for physicians' accountability, it is inevitable that multimedia will play an important role in the foreseeable future and that it will indeed contribute to quality of care. Nonetheless, the views of key players are of great importance in this evolution, and the perspectives of medical professionals in the current surgical climate are poorly known. Therefore, in this cross-disciplinary survey, we aimed to investigate the current viewpoints of surgical specialists and residents in training concerning the use of multimedia recording in the operating room. Inquiries were made regarding their current practice in documenting surgical procedures, their views in regard to the added value and the exact composition of multimedia recordings, and their perspective on possible privacy and legislative issues in this context.

\section{Methods}

On 20 December 2018, members affiliated to the Association of Surgeons of the Netherlands, the Dutch Urological Association and the Dutch Society of Obstetrics and Gynecology were approached by e-mail to engage in a web-based survey (LimeSurvey, LimeSurvey GmbH. Hamburg, Germany). Respondents not wanting to participate in the survey were provided with an opt-out option. Three reminders were sent to non-responders after initial invitation, with an interval of 4 weeks. Retired surgeons, urologists or gynecologists, approached persons with other functions than surgeon, urologist, gynecologist or resident of one of the corresponding disciplines, and partial responses were excluded from analysis.

\section{Questionnaire design}

This questionnaire consists of 16 questions. Questions 1 through 4 covered respondents' demographics. Questions 5 through 9 were multiple choice questions regarding the current use of operative reporting and its serviceability in the future, when developments in technology and an increased call for accountability will likely add to the requirements in medical reporting [17]. Questions 10 through 16 were fivepoint Likert type scales for likelihood or level of objection concerning the use of multimedia in the operating room. The full survey can be found as online supplementary data.

\section{Statistical considerations}

Data were analyzed with IBM SPSS Statistics for Windows, version 25.0 (IBM Corp. Armonk, NY) and Microsoft Excel (Microsoft Corp., Redmond, WA). Data are presented as numbers and percentages. A $P$ value of less than 0.05 was considered statistically significant. Groups were compared using Chi-square test or Fisher's exact test. When responses of two categories were compared within the same group, McNemar's test was used.

\section{Results}

Invitations to a total number of 3151 e-mail addresses were sent, of which 3056 were successfully delivered. The overall response rate was $876(27.8 \%)$. Replies of 197 respondents were excluded from this survey [112 (56.9\%) retired or other function than surgeon, urologist, gynecologist or resident; 85 (43.1\%) partial responses]. After exclusion, a total number of 679 complete questionnaires were analyzed.

Among the respondents, 370 (54.5\%) were surgeons, 71 $(10.5 \%)$ were urologists, $80(11.8 \%)$ were gynecologists, and 158 (23.3) were residents in training of the corresponding disciplines.

Of the respondents, 147 (21.6\%) currently practice their trade in university hospitals, whereas $428(63.0 \%)$ and 82 $(12.1 \%)$ work in general teaching and general non-teaching hospitals, respectively. Respondents' demographics can be found in Table 1.

\section{Perspectives on the current operative report}

Overall, 356 (52.4\%) respondents feel that the currently used narrative operative report-without video and/or sound-is insufficient for future quality requirements [183 (49.5\%) surgeons, 47 (58.8\%) gynecologists, 41 (57.7\%) 
Table 1 Respondent demographics

\begin{tabular}{lc}
\hline & $\begin{array}{l}\text { Specialists } \\
(n=521) \\
N(\%)\end{array}$ \\
\hline $\begin{array}{l}\text { Years practicing } \\
\text { < 5 years }\end{array}$ & $109(20.0)$ \\
$5-10$ years & $129(25.1)$ \\
10-15 years & $102(18.9)$ \\
15-20 years & $88(16.2)$ \\
$>20$ years & $90(18.9)$ \\
\hline & Residents \\
& $(n=158)$ \\
& $N(\%)$ \\
\hline Year of training & \\
Year 1 & $24(15.2)$ \\
Year 2 & $19(12.0)$ \\
Year 3 & $27(17.1)$ \\
Year 4 & $28(17.7)$ \\
Year 5 & $37(23.4)$ \\
Year 6 & $23(14.6)$ \\
\hline
\end{tabular}

urologists and 85 (53.8\%) residents]. There was no significant difference in responses among specialists and between specialists and residents $(P=0.267$ and 0.850 , respectively), nor between differences in practicing years among specialists (less than 5 years, 5-10 years, 10-15 years, 15-20 years or more than 20 years of work experience) or different years of training among residents (year 1 through 6; $P=0.333$ and $P=0.339$, respectively).

\section{Current use of intraoperative multimedia recording}

Table 2 delineates the different techniques which respondents reported to be present in their institution. 630 (92.8\%) of respondents reported the use of endoscopic camera recording. Respectively, 179 (26.4\%) and $85(12.5 \%)$ of respondents indicated that an external camera to record the surgical site, such as a lamp mounted camera, or a camera dedicated to film the surroundings of the operating room, as is the case with the surgical black box among others, is used. A mobile phone is stated to be used to record intraoperative events by 288 (42.4\%).

Overall, $621(91.5 \%)$ of respondents stated that routine video recording of conventional procedures was not common practice in their department. For endoscopic procedures, this number was $186(27.4 \%)$. There was no significant difference within departments $(P=0.791$ and $P=0.640$ for conventional and endoscopic setting respectively). Data of all separate specialties is delineated in Table 3.
Table 2 Reported techniques used in institutions

\begin{tabular}{lc}
\hline & $\begin{array}{l}\text { Respondents } \\
(n=679) \\
N(\%)^{*}\end{array}$ \\
\hline $\begin{array}{l}\text { Endoscopic camera feed } \\
\text { External camera filming the surroundings of the } \\
\text { operating room }\end{array}$ & $630(92.8)$ \\
External camera dedicated to fil the surgical site (e.g. & $179(26.4)$ \\
$\quad$ lamp camera) & $25(3.7)$ \\
Surgical black box & $288(42.4)$ \\
Mobile phone & $25(3.7)$ \\
Sound recorder (microphone) & $23(3.4)$ \\
None of the above & $33(4.9)$ \\
Other &
\end{tabular}

Values represent the number and percentage of respondents answering "yes"

\section{Retention period}

$423(62.3 \%)$ respondents did not know the retention period their institution upholds for video recordings of surgical procedures. Residents know the retention period significantly less often than specialists (120 (75.9\%) vs. $303(58.2 \%)$; $P=<0.001)$. There was no significant difference among specialists (surgeons 217 (58.6) vs. gynecologists $44(55.0 \%)$ vs. urologists $42(59.2 \%) ; P=0.821)$. Of the respondents who do know the retention period in their institution, 20 (2.9\%) reported a retention period of less than 30 days, 109 (16.1\%) between 30 and 90 days, 40 (5.9\%) 90 days and up to a year and lastly $87(12.8 \%)$ reported a period of more than a year.

Table 3 Routine use of intra-operative video recordings, per department

\begin{tabular}{|c|c|c|c|c|c|}
\hline & $\begin{array}{l}\text { Surgery } \\
(n=486)\end{array}$ & $\begin{array}{l}\text { Obstetrics } \\
\text { and Gyne- } \\
\text { cology } \\
(n=112)\end{array}$ & $\begin{array}{l}\text { Urology } \\
(n=81)\end{array}$ & & $\begin{array}{l}\text { Total } \\
(n=679)\end{array}$ \\
\hline & $N(\%)$ & $N(\%)$ & $N(\%)$ & $P$ value & $N(\%)$ \\
\hline \multicolumn{6}{|c|}{ Routine use of video recordings during conventional surgery } \\
\hline Yes & $16(3.3)$ & $2(1.8)$ & $1(1.2)$ & 0.791 & $19(2.8)$ \\
\hline No & $445(91.6)$ & $103(92.0)$ & $73(90.1)$ & & $621(91.5)$ \\
\hline $\begin{array}{l}\text { Don't } \\
\text { know }\end{array}$ & $10(2.1)$ & $3(2.7)$ & $2(2.5)$ & & $15(2.2)$ \\
\hline Missing & $15(3.1)$ & $4(3.6)$ & $5(6.2)$ & & $24(3.5)$ \\
\hline \multicolumn{6}{|c|}{ Routine use of video recordings during endoscopic surgery } \\
\hline Yes & $317(65.2)$ & $73(65.2)$ & $47(58.0)$ & 0.640 & $437(64.4)$ \\
\hline No & $128(26.3)$ & $32(28.6)$ & $26(32.1)$ & & $186(27.4)$ \\
\hline $\begin{array}{l}\text { Don't } \\
\text { know }\end{array}$ & $24(4.9)$ & $3(2.7)$ & $4(4.9)$ & & 31 (4.6) \\
\hline Missing & $17(3.5)$ & $4(3.6)$ & $4(4.9)$ & & $25(3.7)$ \\
\hline
\end{tabular}




\section{Frequency of intraoperative recording}

Overall, the number of respondents answering 'never' or 'almost never' regarding intraoperative video recording was $130(19.1 \%)$ for endoscopic procedures and $483(71.1 \%)$ for conventional procedures. For specialists only, these numbers were $104(20.1 \%)$ for endoscopic procedures and 421 $(81.3 \%)$ for conventional procedures. When comparing specialists in terms of experience level, there was no significant difference ( $P=0.710$ and $P=0.605$ for endoscopic and conventional procedures, respectively). Surgeons significantly more often utilize video recording in open procedures than gynecologists and urologists $(P=0.002)$. There was no significant difference among specialists in regard of work experience; $P=0.710$ and $P=0.605$ for endoscopic and conventional, respectively) as well as among residents in terms of year of training $(P=0.262$ and $P=0.420$ for endoscopic and conventional, respectively).

\section{Purposes of video recording}

Respondents from the surgical department include video in the patient file significantly less often than those from gynecology or urology (41.4\% vs. $55.4 \%$ vs $49.4 \%$, respectively; $P=0.018$ ). There was no significant difference within departments concerning the recording of video files for quality control purposes, educational purposes, or in the context of proctoring (overall percentage 50.5\%, $P=0.070 ; 48.5 \%$, $P=0.341 ; 9.7 \%, P=0.066$, respectively). Respondents from the surgical department record video to provide information for patients and their family or for colleagues significantly less often than those from gynecology or urology (23.9\% vs. $33.0 \%$ vs. $35.8 \%$, respectively; $P=0.021$ ). All purposes for intraoperative video recording reported by respondents are delineated in Table 4.

\section{Behavior in the operating room}

Among all respondents, 397 (58.5\%) responded that it would be "unlikely" or "very unlikely" that they would behave differently during surgery when intra-operative video recording is applied. $562(82.8 \%)$ responded that it would be "unlikely" or "very unlikely" that their surgical methods would be altered by the presence of intra-operative video recording. When intra-operative video and audio recording would be implemented, respondents reported that they would be significantly more likely to behave differently and/ or would alter their surgical methods (reports of "unlikely" or "very unlikely": 232 (34.2\%) $P<0.001$ and 512 (75.4\%) $P<0.001$, respectively). Responses by residents indicated that they would behave differently in the operating room significantly more likely when intraoperative video recording is applied in comparison to responses by specialists (39.7\% vs. $30.2 \% ; P=0.047$, respectively). When inquired about the effect of video and audio recording, this significant difference increases to $71.0 \%$ vs. $56.5 \%(P=0.003)$, respectively. No significant difference among specialists with different experience levels was found regarding the effect on their behavior in the operating room or their surgical methods for both the context of video $(P=0.465$ and $P=0.872$, respectively) and video with audio $(P=0.734$ and $P=0.329)$. Cronbach's alpha of internal consistency for five-point Likert type scale questions in this section was 0.871 .

\section{Privacy and legal concerns}

In the context of the recognizability of the respondent in the situation of intraoperative video recording, 252 (37.1\%) of respondents find this either "objectionable" or "very objectionable". 358 (52.7\%) find it either "objectionable" or "very objectionable" to be recorded on intra-operative video in regards of medical liability. Finally, 241 (35.5\%) find it either "objectionable" or "very objectionable" to be recorded on intra-operative video in the context of quality
Table 4 Purposes of video recording

\begin{tabular}{|c|c|c|c|c|c|}
\hline & $\begin{array}{l}\text { Surgery } \\
(n=486)\end{array}$ & $\begin{array}{l}\text { Obstetrics and } \\
\text { Gynecology } \\
(n=112)\end{array}$ & $\begin{array}{l}\text { Urology } \\
(n=81)\end{array}$ & & $\begin{array}{l}\text { Total } \\
(n=679)\end{array}$ \\
\hline & $N(\%)$ & $N(\%)$ & $N(\%)$ & $P$ value & $N(\%)$ \\
\hline Addition to patient file & $201(41.4)$ & $62(55.4)$ & $40(49.4)$ & 0.018 & $303(44.6)$ \\
\hline For quality control purposes & $232(47.7)$ & $65(58.0)$ & $46(56.8)$ & 0.070 & $343(50.5)$ \\
\hline For educational purposes & $238(49.0)$ & $48(42.9)$ & $43(53.1)$ & 0.341 & $329(48.5)$ \\
\hline In the context of proctoring & $55(11.3)$ & $5(4.5)$ & $6(7.4)$ & 0.066 & $66(9.7)$ \\
\hline $\begin{array}{l}\text { To provide information for } \\
\text { patients, family and/or col- } \\
\text { leagues }\end{array}$ & $116(23.9)$ & $37(33.0)$ & $29(35.8)$ & 0.021 & $182(26.8)$ \\
\hline Other & $32(6.6)$ & $5(4.5)$ & $5(6.2)$ & & $42(6.2)$ \\
\hline
\end{tabular}

Values represent the number of respondents selecting the given purposes as a reason for video recording 
of surgical care. Among specialists, there was no significant difference concerning the years of practice in the context of recognizability or medical liability $(P=0.589$ and $P=0.071)$. In the context of quality of surgical care, there was a significant difference between the different levels of experience $(P<0.001)$, with those who are less experienced (5 years or less) more likely to object compared to those with the most experience (20 years or more; $53(68.8 \%)$ vs 21 (32.3\%), respectively). Cronbach's alpha of internal consistency for these questions was 0.726 .

\section{Added value of intra-operative video and sound recording}

$409(60.2 \%)$ and $222(32.7 \%)$ respondents recognized the added value of intraoperative video and intraoperative video with sound as either "likely" or "very likely". 602 (88.7\%) and $419(61.7 \%)$ deemed this for educational purposes. 302 (44.5) and 148 (21.8\%), respectively, found intraoperative video and intraoperative video with sound useful in providing information for patients, family and/or colleagues. $411(60.5 \%)$ and $269(39.6 \%)$ saw potential in the use of these respective modalities for quality control purposes. 453 (66.7\%) and 312 (45.9\%) deemed it likely that intraoperative video and intraoperative video with sound respectively would be an addition in the context of proctoring. Finally, $378(55.7 \%)$ and $282(41.5 \%)$ of respondents found it likely that intraoperative video and intraoperative video with sound could play a supportive role in medicolegal proceedings.

Cronbach's alpha of internal consistency for these questions was 0.84 .

\section{Preferred recording method for intraoperative registration}

Table 5 lists an overview of preferred recording methods. $433(63.8 \%)$ of respondents preferred only video if registration of the surgical procedure was implemented. 144 (21.2\%) preferred video and audio recording. 84 (12.4\%) would rather not have any recording at all. 18 (2.7) did not submit any preference.

\section{Discussion}

An increasing number of studies are exploring the values of multimedia recording in the surgical setting today. Some are exploring its role in surgical quality analysis and control $[4-6,16,18]$. Some assess its part in the amelioration of operative reporting $[6,14]$. Others examine its part in surgical education [19-21]. While each an addition to the growing knowledge on this matter, none are currently implemented in a widespread manner. End users, in this case the surgical specialists, have yet to voice themselves regarding their viewpoint in intraoperative video and audio recording. To our knowledge, this study has been the first to do so.

About half of the respondents agree with the statement that the currently used narrative operative report, without the addition of intraoperative video and/or sound, is lacking for future quality requirements. Today, the majority of institutions use either dictation devices, typed reports or modified pre-written concept reports. This method of reporting, however, is subjective by nature and often lacks essential information $[4,14]$.

As expected, endoscopic procedures are far more often recorded by respondents compared to conventional ("open") procedures. This is mostly due to the fact that the endoscope's camera function is essential to conduct minimally invasive surgery. Video recording could then be implemented at the press of a button. Therefore, far less use a different, dedicated modality to record surgical procedures on video, such as a camera mounted to the surgical lamp (26.4\%) or a fixed camera in the operating room $(12.5 \%)$. Often, the quality is lacking, or the operator's head and body are in its line of sight. Furthermore, for dynamic procedures, such as in orthopedic surgery or vascular surgery, it is virtually impossible to capture the essential moments through this method. Noteworthy is the use of mobile phones to record certain aspects of the surgery; about half of respondents have stated to use their mobile phone. This is probably due to the ease of use and the possibility to use the phone's video call function to consult colleagues or other specialists.
Table 5 Preferred recording method for intraoperative registration

\begin{tabular}{lc}
\hline Statements & $\begin{array}{l}\text { All respondents } \\
(n=679) \\
N(\%)\end{array}$ \\
\hline Video recordings of the entire surgical procedure & $211(31.1)$ \\
Video recordings of only the essential steps of the surgical procedure & $222(32.7)$ \\
Video and audio recordings of the entire surgical procedure & $77(11.3)$ \\
Video and audio recordings of only the essential steps of the surgical procedure & $67(9.9)$ \\
No video and audio recordings & $84(12.4)$ \\
No preference & $18(2.7)$ \\
\hline
\end{tabular}


More than half of respondents did not know the duration of the retention period for intraoperative video recordings in their institution. Most that did know, reported a retention period between 30 and 90 days. Rules regarding the production and handling of medical documentation have been laid down in the Health Insurance Portability and Accountability Act (HIPAA) for the United States and the European General Data Protection Regulation for the European Union [22, 23]. However, a specific time period is stipulated in neither. Instead, referral to local legislation is made.

The results of this survey suggest that surgeons are less likely than urologists and gynecologists to include video in the patient file or to record video to provide information for patients and family. A possible explanation is the fact that both of the latter specialties perform endoscopic procedures such as hysteroscopy and cystoscopy, during which it is customary to include photography or video with the report.

The majority $(58.5 \%)$ would think it is unlikely they would behave differently during surgery when intra-operative video recording is applied. Even more (82.8\%) think it is unlikely that their surgical methods would be altered. An important finding is the fact that residents among respondents find it significantly less unlikely that their behavior or surgical method would be altered $(34.2 \%$ and $75.4 \%$, respectively). Being in specialist training, it is important for residents to feel at ease and to be able to perform their surgery with as less additional pressure as possible. However, as our previous study has demonstrated, the role of intraoperative video recording in behavioral modification, also known as the "Hawthorne effect", is negligible [6].

A major concern related to the recording of intraoperative video (and audio) is the risks regarding the privacy of the patient and the operating room personnel alike. This is illustrated by the fact that over a third of respondents find it objectionable to be recognized on intraoperative video recording. Regarding possible medico-legal liability, over half of respondents find it objectionable.

At this moment it is unclear when and for what purposes and by whom these recordings could be accessed. International legal texts mainly focus on the individual's privacy, and are yet to incorporate specific situations for the surgical setting [22-24].

Overall, the majority of respondents consider the added value of intraoperative video recording for multiple uses. This is less for intraoperative audio recording. The main sentiment in this regard is about significant loss of privacy. For instance, many respondents commented that in the operating room it is of great importance to be able to talk about non-work-related issues for an adequate balance between focus and being at ease. Sometimes, these topics can be of intimate nature. Without the proper delineation of who is able to access such audio recordings, most fear for their privacy and current job satisfaction.
$55.7 \%$ and $41.5 \%$ of respondents recognized the benefit of intraoperative video recording and combined video- and audio recording, respectively, in regard to its supportive role in medicolegal proceedings. In contrary of what is often feared, intraoperative recording could aid in medicolegal proceedings, instead of merely posing risk for medical negligence [25]. The importance of an intraoperative event is often not able to be appraised by an operator during the procedure. Therefore, in this scenario, systematic recording of a procedure in its entirety is necessary, not merely of a selection of procedures or at certain moments when the surgeon "feels like it".

This survey yielded a response rate of $27.8 \%$, a rate similar to other surveys having approached a comparable number of possible respondents [26]. Also, due to the larger number of invitations, this survey included a high number of replies. With this response rate, however, there is risk for possible imbalance among respondents, e.g. respondents more interested in laparoscopic surgery, in which video recording is already operational, might be more outspoken concerning intraoperative video, compared to respondents of which the majority of procedures are "open surgery" (e.g. transplant surgery, vascular surgery, or trauma surgery).

As the results of this study suggest, the surgical landscape is still divided in terms of intraoperative multimedia recording. Whilst the majority of respondents feel the current method of surgical reporting is insufficient and a large portion are open to the idea of documenting the operative phase on video or audio, there are still certain issues to be sorted out before implementation could be considered. First of all, a significant portion of respondents expressed their concern in regard to potential privacy infringement. Currently no specific law is in effect to shield healthcare providers for their exposure when being recorded during practice. Furthermore, the issue in terms of ownership has not been resolved yet. Up to now, all documentation in healthcare, albeit written, photographed or recorded, are incorporated in the patient file, rendering it patient property by law. In this case, no protection for the healthcare provider is specifically implemented. It is, therefore, imperative that specific legislation will be developed for these methods of intraoperative documentation to adequately protect all subjects in the recordings as well as securing ease of use and harnessing its potential in quality and safety procurement.

In conclusion, the majority of respondents find the current method of operative recording insufficient for future quality requirements. There is support for intraoperative video recording, however, most respondents fear privacy infringement. These concerns are greater for audio recording compared to video recording only. Legislation is necessary before either intraoperative video or audio recording could be implemented to protect not only the patients, but also the healthcare providers. 
Author contribution Conceptualization: FWG, ÖE, JFL; Methodology: FWG, ÖE, JFL; Formal analysis and investigation: FWG, ÖE, JFL; Writing — original draft preparation: FWG, ÖE; Writing—review and editing: FWG, ÖE, JFL; Supervision: JFL.

\section{Compliance with ethical standards}

Conflict of interest The authors declare no conflicts of interest.

Research involving human participants and/or animals This article did not contain any studies involving human participants, as it utilizes survey data.

Informed consent Participation in the survey was anonymous and voluntary. Informed consent was included upon participation to the survey.

Open Access This article is licensed under a Creative Commons Attribution 4.0 International License, which permits use, sharing, adaptation, distribution and reproduction in any medium or format, as long as you give appropriate credit to the original author(s) and the source, provide a link to the Creative Commons licence, and indicate if changes were made. The images or other third party material in this article are included in the article's Creative Commons licence, unless indicated otherwise in a credit line to the material. If material is not included in the article's Creative Commons licence and your intended use is not permitted by statutory regulation or exceeds the permitted use, you will need to obtain permission directly from the copyright holder. To view a copy of this licence, visit http://creativecommons.org/licenses/by/4.0/.

\section{References}

1. Plaisier PW, Pauwels MM, Lange JF (2001) Quality control in laparoscopic cholecystectomy: operation notes, video or photo print? HPB 3(3): 197-199

2. Evidence based guideline (2016) Diagnosis and treatment of cholelithiasis. https://heelkunde.nl/sites/heelkunde.nl/files/richt lijnen-definitief/Richtlijn_Galsteenlijden_09032016.pdf

3. Sanford DE, Strasberg SM (2014) A simple effective method for generation of a permanent record of the critical view of safety during laparoscopic cholecystectomy by intraoperative "doublet" photography. J Am Coll Surg 218(2):170-178

4. Wauben LS, van Grevenstein WM, Goossens RH, van der Meulen FH, Lange JF (2011) Operative notes do not reflect reality in laparoscopic cholecystectomy. Br J Surg 98(10):1431-1436

5. van de Graaf FW, Lange MM, Menon AG, O'Mahoney PR, Milsom JW, Lange JF (2016) Imaging for quality control: comparison of systematic video recording to the operative note in colorectal cancer surgery. A pilot study. Ann Surg Oncol 23:798-803

6. van de Graaf FW, Lange MM, Spakman JI, van Grevenstein WMU, Lips D, de Graaf EJR et al (2019) Comparison of systematic video documentation with narrative operative report in colorectal cancer surgery. JAMA Surgery 154(5):381-389

7. Eng JL, Baliski CR, McGahan C, Cai E (2018) Uptake and impact of synoptic reporting in a community care setting. Am J Surg 215:857-861

8. Gur I, Gur D, Recabaren JA (2012) The computerized synoptic operative report: a novel tool in surgical residency education. Arch Surg 147(1):71-74

9. Harvey A, Zhang H, Nixon J, Brown CJ (2007) Comparison of data extraction from standardized versus traditional narrative operative reports for database-related research and quality control. Surgery (USA) 141(6):708-714

10. Maniar RL, Hochman DJ, Wirtzfeld DA, McKay AM, Yaffe CS, Yip B et al (2014) Documentation of quality of care data for colon cancer surgery: comparison of synoptic and dictated operative reports. Ann Surg Oncol 21(11):3592-3597

11. Maniar RL, Sytnik P, Wirtzfeld DA, Hochman DJ, McKay AM, Yip B et al (2015) Synoptic operative reports enhance documentation of best practices for rectal cancer. J Surg Oncol 112(5):555-560

12. Stogryn SE, Hardy K, Mullan MJ, Park J, Andrew C, Vergis A (2018) Synoptic operative reporting: assessing the completeness, accuracy, reliability, and efficiency of synoptic reporting for Rouxen-Y gastric bypass. Surg Endosc Interv Tech 32(4):1729-1739

13. Eryigit Ö, van de Graaf FW, Lange JF (2019) A systematic review on the synoptic operative report versus the narrative operative report in surgery. World J Surg 43:2175-2185

14. Eryigit O, van de Graaf FW, Nieuwenhuijs VB, Sosef MN, de Graaf EJR, Menon AG et al (2020) Association of video completed by audio in laparoscopic cholecystectomy with improvements in operative reporting. JAMA Surg 155:617-623

15. Birkmeyer JD, Finks JF, O'Reilly A, Oerline M, Carlin AM, Nunn AR et al (2013) Surgical skill and complication rates after bariatric surgery. N Engl J Med 369(15):1434-1442

16. Bonrath EM, Gordon LE, Grantcharov TP (2015) Characterising 'near miss' events in complex laparoscopic surgery through video analysis. BMJ Qual Saf 24(8):516-521

17. Vaughan S (2018) Current state and future directions of medical specialties internationally: joint project by the Australian Medical Council and the Medical Specialties Council of the Royal Dutch Medical Association

18. Walsh PC, Marschke P, Ricker D, Burnett AL (2000) Use of intraoperative video documentation to improve sexual function after radical retropubic prostatectomy. Urology 55(1):62-67

19. Driscoll PJ, Paisley AM, Paterson-Brown S (2008) Video assessment of basic surgical trainees' operative skills. Am J Surg 196(2):265-272

20. Evans HL, O'Shea DJ, Morris AE, Keys KA, Wright AS, Schaad DC et al (2016) A comparison of Google Glass and traditional video vantage points for bedside procedural skill assessment. Am J Surg 211(2):336-342

21. Rehim SA, Chung KC (2015) Educational video recording and editing for the hand surgeon. J Hand Surg Am 40(5):1048-1054

22. Health Insurance Portability and Accountability Act of 199.

23. Regulation (EU) 2016/679 of the European Parliament and of the Council of 27 April 2016 on the protection of natural persons with regard to the processing of personal data and on the free movement of such data, and repealing Directive 95/46/EC (General Data Protection Regulation).

24. Henken KR, Jansen FW, Klein J, Stassen LPS, Dankelman J, van den Dobbelsteen JJ (2012) Implications of the law on video recording in clinical practice. Surg Endosc 26(10):2909-2916

25. Hoschtitzky JA, Trivedi DB, Elliott MJ (2009) Saved by the video: added value of recording surgical procedures on video. Ann Thorac Surg 87(3):940-941

26. van de Graaf FW, van den Bos J, Stassen LPS, Lange JF (2018) Lacunar implementation of the critical view of safety technique for laparoscopic cholecystectomy: results of a nationwide survey. Surgery 164:31-39

Publisher's Note Springer Nature remains neutral with regard to jurisdictional claims in published maps and institutional affiliations. 